\title{
Safety and Effectiveness of Laparoscopic Colorectal Resection in Elderly Patients with Colorectal Cancer: A Propensity Score Matching Study
}

\author{
AKIRA ARIMOTO ${ }^{1}$, HIROSHI HASEGAWA ${ }^{1}$, HIROKAZU SUGIYAMA ${ }^{2}$, KIMIHIRO YAMASHITA $^{1}$, \\ TAKERU MATSUDA ${ }^{1}$, MASAHIRO TOMINAGA ${ }^{2}$, YASUO SUMI ${ }^{3}$, SATOSHI SUZUKI ${ }^{1}$ and YOSHIHIRO KAKEJI ${ }^{1}$ \\ ${ }^{1}$ Department of Surgery, Division of Gastrointestinal Surgery, \\ Kobe University Graduate School of Medicine, Kobe, Japan; \\ ${ }^{2}$ Department of Gastroenterogical Surgery, Hyogo Cancer Center, Akashi, Japan; \\ ${ }^{3}$ Department of Gastrointestinal Surgery, International Clinical Cancer Research Center, Kobe, Japan
}

\begin{abstract}
Background/Aim: The aim of this study was to evaluate the safety and effectiveness of laparoscopic surgery in elderly patients with colorectal cancer. Patients and Methods: In total, 223 patients aged $<75$ years and 66 patients aged $\geq 75$ years who underwent laparoscopic colorectal resection were included. Short- and long-term outcomes were compared between the younger and elderly patients after propensity score matching. Results: Post-operative complications were similar in both groups (younger vs. elderly: $24.7 \%$ vs. $19.3 \%$, $p=0.479)$. There were no significant differences in disease-free survival (DFS) (5-year DFS: $96.3 \%$ vs. $86.9 \%, p=0.079)$ and overall survival (OS) (5-year OS: $92.9 \%$ vs. $78.1 \%, p=0.106)$ between the two groups. Conclusion: Laparoscopic surgery for colorectal cancer is as safe and effective for elderly patients as for younger patients.
\end{abstract}

Colorectal cancer (CRC) is the most commonly occurring cancer and the second leading cause of cancer-related deaths in Japan. In developed countries, the average life expectancy is remarkably increasing, and thus, the mean age of patients who are diagnosed with colorectal cancer is also increasing. Many studies have reported that laparoscopic colorectal resection for colorectal cancer is less invasive than open surgery, resulting in better short-term outcomes and substantially equal functional and oncological results (1-4).

Correspondence to: Akira Arimoto, Department of surgery, Division of Gastrointestinal Surgery, Kobe University Graduate School of Medicine, 7-5-2 Kusunoki-cho, Chuo-ku, Kobe, Hyogo 650-0017, Japan. Tel: +81 7835925, Fax: +81 783825939, e-mail: aarimoto@med.kobe-u.ac.jp

Key Words: Laparoscopic colorectal resection, elderly, long-term outcome, propensity score matching.
Most of these studies limit the patient's age to $<75$ years; it has been reported that elderly patients with colorectal cancer have more post-operative complications (5) and lower survival rate than younger ones (6). It is unclear whether laparoscopic surgery in elderly patients with colorectal cancer is as safe and effective as in relatively younger patients. Therefore, we aimed to evaluate its safety and effectiveness in elderly patients with colorectal cancer in terms of short- and long-term outcomes.

\section{Patients and Methods}

Patient selection. Data from patients with primary colorectal cancer who underwent laparoscopic colorectal resection at the Kobe University Hospital or Hyogo Cancer Center between 2006 and 2011 were retrospectively collected and analyzed. Patients with low rectal cancer were excluded. We defined patients aged $\geq 75$ years as elderly in this study.

Surgical procedure. All laparoscopic surgeries were intended to be radical resections, and palliative surgeries were excluded. Radical resection was defined according to the Japanese Society for Cancer of the Colon and Rectum (JSCCR) Guidelines 2005, 2009, and 2010 for the treatment of colorectal cancer (7-9). Cases with microscopic residual tumor (R1) or macroscopic residual tumor (R2) were excluded. Conversion to open surgery was defined as a larger vertical abdominal incision than that necessary to retrieve the specimen, and the reasons were analyzed.

Study design and study outcomes. The following patient characteristics were examined: age, sex, body mass index (BMI), the American Society of Anesthesiologists (ASA) score, comorbidities, the laparoscopic procedure performed, and the pathological stage (UICC). Comorbidities were numerically converted into Charlson Comorbidity Index (CCI) scores. Operative and post-operative data included operative time, blood loss, conversion to open surgery, complications and post-operative hospital days. Long-term outcomes were analyzed along with disease-free survival (DFS) and overall survival (OS). All data between the elderly and younger groups were compared. 


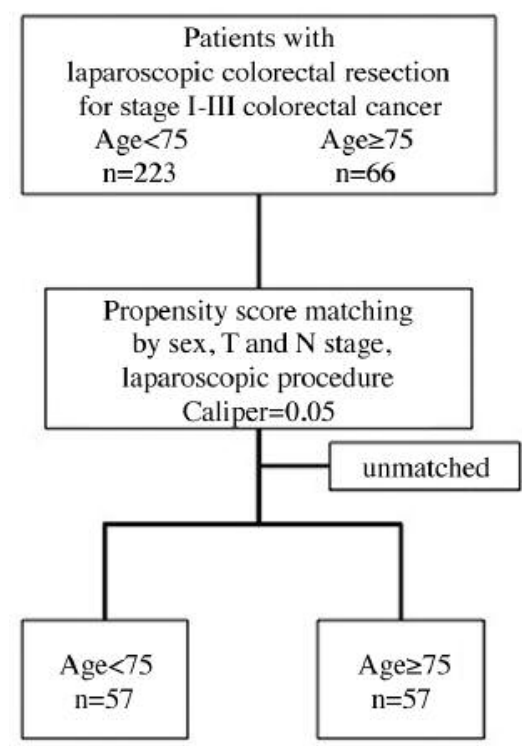

Figure 1. Flowchart of patient selection.

Statistical analysis. Propensity score matching was used to balance some covariates that may affect long-term outcomes. The following covariates were included in the score matching: sex, $\mathrm{T}$ and $\mathrm{N}$ stage (UICC), and the laparoscopic procedure performed. Continuous values were expressed as median and range and were analyzed using the Mann-Whitney $U$-test. Categorical values were expressed as percentages and were analyzed using the chi-square and Fisher's exact tests. DFS and OS were analyzed using Kaplan-Meier analysis and the log-rank test. Significance was defined as $p<0.05$. Statistical analyses including propensity score matching were performed using the JMP software (SAS Institute Inc., Cary, NC).

\section{Results}

A total of 223 younger patients and 66 elderly patients undergoing laparoscopic colorectal resection for colorectal cancer were identified in our database. Figure 1 shows the flow chart used for patient selection in this study. Finally, 57 pairs were matched and analyzed.

Demographic and disease-related data after propensity score matching are shown in Tables I and II, respectively. ASA and CCI scores were significantly higher in elderly patients. There were no significant differences in sex, BMI, the laparoscopic procedure performed, the $\mathrm{T}$ and $\mathrm{N}$ stage, and the pathological stage between the two groups.

The perioperative data and short-term outcomes for propensity score matched patients are summarized in Table III. There were no significant differences in operative time or blood loss, and overall complications were similar between the two groups. The conversion rate was significantly higher in elderly patients.
Table I. Demographics in younger (age $<75)$ and elderly (age $\geq 75$ ) patients.

\begin{tabular}{lccc}
\hline & $75<(\mathrm{n}=57)$ & $\leq 75(\mathrm{n}=57)$ & $p$-Value \\
\hline Age & $63.2 \pm 8.4$ & $79.7 \pm 3.7$ & \\
Gender (male/female) & $32 / 25$ & $33 / 24$ & 0.850 \\
BMI & $22.2 \pm 0.4$ & $21.4 \pm 0.4$ & 0.224 \\
ASA & & & 0.001 \\
1 & $20(35.1 \%)$ & $4(7.0 \%)$ & \\
2 & $30(52.6 \%)$ & $40(70.2 \%)$ & \\
3 & $7(12.3 \%)$ & $13(22.8 \%)$ & \\
CCI & & & \\
$0-2$ & $53(93.0 \%)$ & $45(79.0 \%)$ & 0.031 \\
$3 \leq$ & $4(7.0 \%)$ & $12(21.1 \%)$ & \\
\hline
\end{tabular}

Table II. Disease-related data of both groups.

\begin{tabular}{lccc}
\hline & $75<(\mathrm{n}=57)$ & $\leq 75(\mathrm{n}=57)$ & $p$-Value \\
\hline Laparoscopic Procedure & & & 0.987 \\
Iliocolic resection & $4(7.0 \%)$ & $5(8.8 \%)$ & \\
Right colectomy & $24(42.1 \%)$ & $22(38.6 \%)$ & \\
Transverse colon Resection & $3(5.3 \%)$ & $3(5.3 \%)$ & \\
Left colectomy & $1(1.8 \%)$ & $2(3.5 \%)$ & \\
Sigmoid colon resection & $17(30.0 \%)$ & $16(28.1 \%)$ & \\
Rectal resection & $8(14.0 \%)$ & $9(15.8 \%)$ & \\
T stage & & & 0.708 \\
T1 & $13(22.8 \%)$ & $10(17.5 \%)$ & \\
T2 & $3(5.3 \%)$ & $3(5.3 \%)$ & \\
T3 & $40(70.2 \%)$ & $41(71.9 \%)$ & \\
T4 & $1(1.8 \%)$ & $3(5.3 \%)$ & \\
N stage & & & 0.536 \\
N0 & $44(77.2 \%)$ & $41(71.9 \%)$ & \\
N1 & $13(22.8 \%)$ & $15(26.3 \%)$ & \\
N2 & $0(0 \%)$ & $1(1.8 \%)$ & \\
Pathological Stage & & & 0.812 \\
I & $13(22.8 \%)$ & $12(21.1 \%)$ & \\
II & $31(54.4 \%)$ & $29(59.9 \%)$ & \\
III & $13(22.8 \%)$ & $16(28.1 \%)$ & \\
\hline
\end{tabular}

Table III. Perioperative data and short-term outcomes of both groups

\begin{tabular}{lccc}
\hline & $75<(\mathrm{n}=57)$ & $\leq 75(\mathrm{n}=57)$ & $\mathrm{p}$-Value \\
\hline Operative time (min) & $267[119-664]$ & $239[128-464]$ & 0.291 \\
Blood loss (ml) & $30[0-846]$ & $30[0-2709]$ & 0.910 \\
Conversion & $0(0 \%)$ & $4(7.0 \%)$ & 0.042 \\
Total complication & $14(24.7 \%)$ & $11 \%(19.3 \%)$ & 0.479 \\
$\quad$ Surgical site infection & $3 \%(5.3 \%)$ & $4(7.0 \%)$ & 0.696 \\
Intraabdominal abscess & $1(1.8 \%)$ & $1(1.8 \%)$ & 1.000 \\
Anastomotic leakage & $4(7.0 \%)$ & $2(3.5 \%)$ & 0.401 \\
Ileus & $0(0 \%)$ & $2(3.5 \%)$ & 0.154 \\
Respiratory complication & $1(1.8 \%)$ & $0(0 \%)$ & 0.315 \\
Post-operative hospital & & & \\
stay (days) & $12[6-43]$ & $13[5-107]$ & 0.100 \\
\hline
\end{tabular}


A

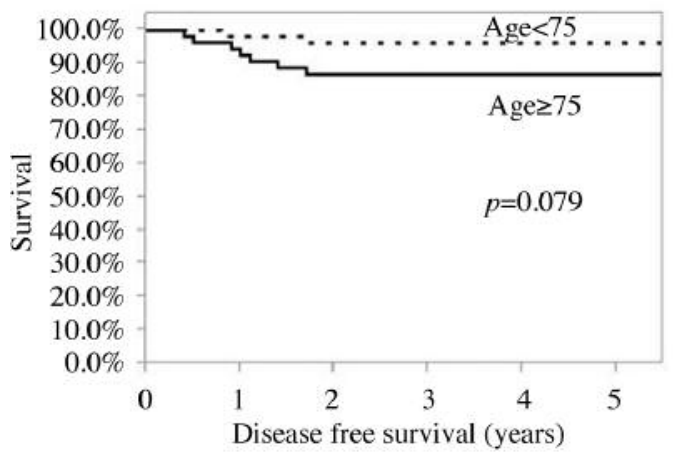

B

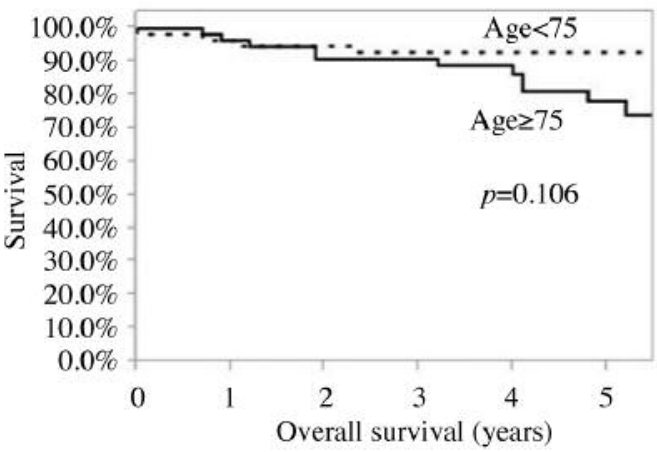

Figure 2. Disease free survival (A) and overall survival (B) of both groups.

Adjuvant chemotherapy was applied in 12 out of 57 $(21.4 \%)$ younger and five out of $57(8.8 \%)$ elderly patients $(p=0.06)$.

The median overall follow-up time was 4.8 years in younger patients and 4.5 years in elderly patients. Figure 2 shows DFS and OS curves for each group. DFS was better in younger patients; however, there was no significant difference (5-year DFS: 96.3\% vs. 86.9\%, $p=0.079)$. OS was similar in both groups (5-year OS: $92.9 \%$ vs. $78.1 \%, p=0.106$ ).

\section{Discussion}

The purpose of this study was to evaluate whether laparoscopic surgery for colorectal cancer in elderly patients is as safe and effective as that for younger patients. This is the first study in which long-term survival after laparoscopic colorectal resection was compared between younger and elderly patients after matching oncological characteristics using propensity score matching. We demonstrated that there were no differences in operative and post-operative outcomes and long-term survival between the elderly and younger groups.

In the present study, elderly patients had higher ASA and CCI scores than younger patients as expected, which showed their general frailty. Kirchhoff et al. reported that an age of $\geq 75$ years was one of the risk factors that caused intra- and post-operative complications (5). However, there was no difference in short-term outcomes because of not only the less invasive of laparoscopic surgery but also the development of perioperative treatment.

Only a few studies have compared long-term outcomes of laparoscopic surgery between elderly and younger patients $(8,9)$. In the present study, the five-year DFS and OS were $96.3 \%$ and $92.9 \%$ in younger patients and $86.9 \%$ and $78.1 \%$ in elderly patients, respectively. Even in each pathological stage, there were no significant differences in OS and DFS (Figure 3 and data not shown). These results were similar to existing reports.
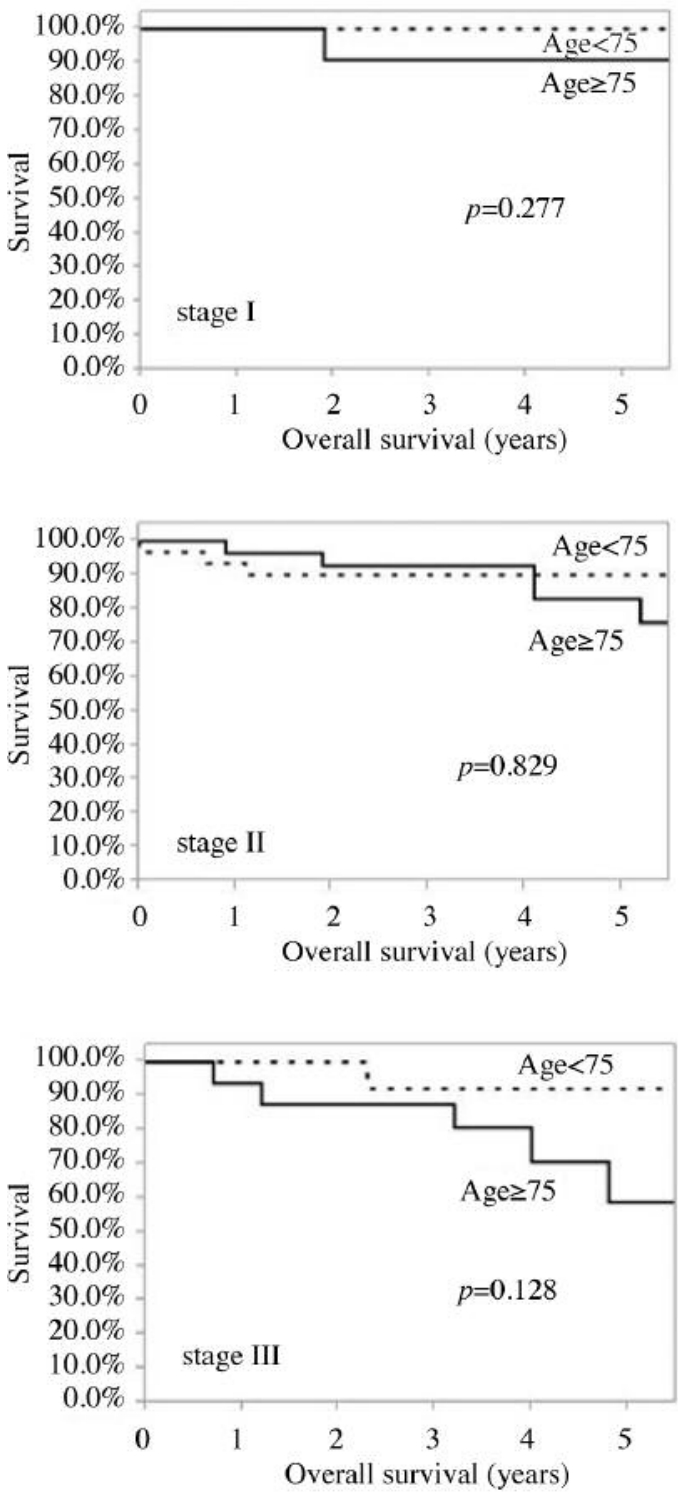

Figure 3. Overall survival (B) of both groups in each stage. 
Many studies have reported the utility of adjuvant chemotherapy in elderly patients resulting in better recurrentfree survival and OS $(10,11)$. For the treatment of colorectal cancer, we generally follow the JSCCR Guidelines (7), which recommend adjuvant chemotherapy for patients with stage III colorectal cancer (presence of lymph node metastasis). While the UICC and JSCCR classifications are slightly different, patients with stage III cancer (UICC) in the present study were indicated for adjuvant chemotherapy. Adjuvant chemotherapy was more often applied in younger patients in the present study. Reasons for elderly patients not receiving adjuvant chemotherapy were rejection and comorbidities. The five-year survival of stage III patients was not significantly different between the groups; however, the survival in elderly patients tended to be worse than that in younger patients, possibly due to reduced adjuvant chemotherapy administration.

The conversion rate to open surgery was significantly higher in elderly patients. Four patients in the elderly group were converted to open surgery because of invasion into another organ $(n=2)$, bleeding $(n=1)$, or unknown reason $(n=1)$. We suspect that when operating on elderly patients, surgeons may have a tendency to convert to open surgery earlier considering the patient's frailty and longer operation time, which could lead to post-operative complications. In the present study, one patient with conversion had surgical site infection. It is controversial whether conversion to open surgery and resulting complications lead to poorer survival $(12,13)$.

The limitations of the present study were due to patient selection. First, we included only R0 resected cases in this study, which could produce better survival rates than in clinical practice. Second, the median BMI of patients selected in this study was relatively low in both groups compared with existing studies. Obesity is an important factor that affects the quality of surgery. Hence, the patients included in this study may not reflect the general population in terms of body type.

In conclusion, this study demonstrated that laparoscopic colorectal resection for colorectal cancer in elderly patients was as safe and effective as that for younger patients.

\section{Conflicts of Interest}

The Authors declare no conflicts of interest.

\section{References}

1 Clinical Outcomes of Surgical Therapy Study Group, Nelson H, Sargent DJ, Wieand HS, Fleshman J, Anvari M, Stryker SJ, Beart RW Jr, Hellinger M, Flanagan R Jr., Peters W and Ota D: A comparison of laparoscopically assisted and open colectomy for colon cancer. N Engl J Med 350: 2050-2059, 2004.

2 Lacy AM, García-Valdecasas JC, Delgado S, Castells A, Taurá P, Piqué JM and Visa J: Laparoscopy-assisted colectomy versus open colectomy for treatment of non-metastatic colon cancer: A randomised trial. Lancet 359: 2224-2229, 2002.
3 Fleshman J, Sargent DJ, Green E, Anvari M, Stryker SJ, Beart RW, Hellinger M, Flanagan RF, Peters W and Nelson H: Laparoscopic colectomy for cancer is not inferior to open surgery based on 5-year data from the COST Study Group trial. Ann Surg 246: 655-662, 2007.

4 Bonjer HJ, Deijen CL, Abis GA, Cuesta MA, van der Pas MHGM, de Lange-de Llerk ESM, Lacy AM, Bemelman WA, Andersson J, Angenete E, Rosenberg J, Fuerst A and Haglind E: A Randomized Trial of Laparoscopic versus Open Surgery for Rectal Cancer. N Engl J Med 372: 1324-1332, 2015.

5 Kirchhoff P, Dincler S and Buchmann P: A multivariate analysis of potential risk factors for intra- and postoperative complications in 1316 elective laparoscopic colorectal procedures. Ann Surg 248: 259-265, 2008.

6 Colorectal Cancer Collaborative Group. Surgery for colorectal cancer in elderly patients: a systematic review. Lancet 356 : 968974, 2000.

7 The Japanese Society for Cancer of the Colon and Rectum. JSCCR Guidelines 2005 for the Treatment of Colorectal Cancer. Kanehara \& Co., Tokyo, 2005.

8 The Japanese Society for Cancer of the Colon and Rectum. JSCCR Guidelines 2009 for the Treatment of Colorectal Cancer. Kanehara \& Co., Tokyo, 2009.

9 Watanabe T, Itabashi M, Shimada Y, Tanaka S, Ito Y, Ajioka Y, Hamaguchi T, Hyodo I, Igarashi M, Ishida H, Ishiguro M, Kanemitsh Y, Kokudo N, Muro K, Ochiai A, Oguchi M, Ohkura Y, Saito Y, Sakai Y, Ueno H, Yoshino T, Fujimori T, Koinuma N, Morita T, Nishimura G, Sakata Y, Takahashi K, Takiuchi H, Tsuruta O, Yamaguchi T, Yoshida M, Yamaguchi N, Kotake K and Sugihara K: Japanese Society for Cancer of the Colon and Rectum (JSCCR) guidelines 2010 for the treatment of colorectal cancer. Int J Clin Oncol 17: 1-29, 2012.

10 Nitsche U, Späth C, Müller TC, Maak M, Janssen KP, Wilhelm D, Kleeff J and Bader FG: Colorectal cancer surgery remains effective with rising patient age. Int J Colorectal Dis 29: 971-979, 2014.

11 Tokuhara K, Nakatani K, Ueyama Y, Yoshioka K and Kon M: Short- and long-term outcomes of laparoscopic surgery for colorectal cancer in the elderly: A prospective cohort study. Int J Surg 27: 66-71, 2016.

12 Sargent DJ, Goldberg RM, Jacobson SD, Macdonald JS, Labianca R, Haller DG, Shepherd LE, Seitz JF and Francini G: A pooled analysis of adjuvant chemotherapy for resected colon cancer in elderly patients. NEnglJMed 345: 1091-1097, 2001.

13 Lund CM, Nielsen D, Dehlendorff C, Christiansen AB, Rønholt F, Johansen JS and Vistisen KK: Efficacy and toxicity of adjuvant chemotherapy in elderly patients with colorectal cancer: the ACCORE study. ESMO Open 1: e000087, 2016.

14 Allaix ME, Degiuli M, Arezzo A, Arolfo S and Morino M: Does conversion affect short-term and oncologic outcomes after laparoscopy for colorectal cancer? Surg Endosc Other Interv Tech 27: 4596-4607, 2013.

15 Clancy C, O’Leary DP, Burke JP, Redmond HP, Coffey JC, Kerin MJ and Myers E: A meta-analysis to determine the oncological implications of conversion in laparoscopic colorectal cancer surgery. Color Dis 17: 482-490, 2015.

Received June 2, 2017

Revised June 15, 2017

Accepted June 16, 2017 